
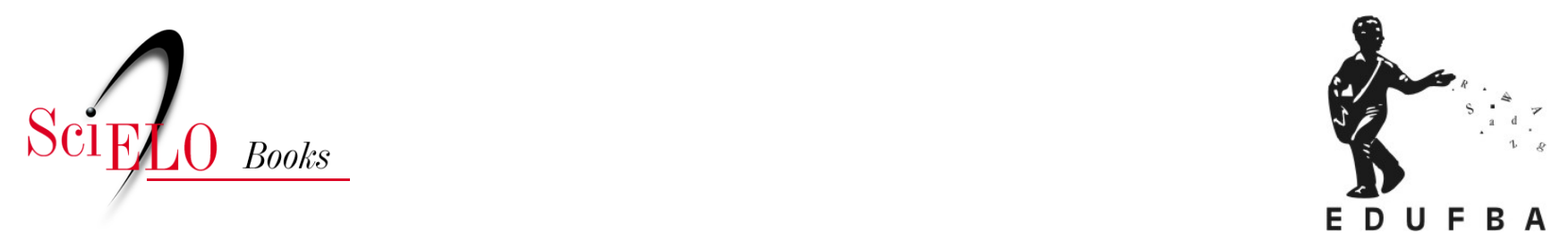

\title{
As configurações políticas do Trabalho Infantil Doméstico
}

\author{
Danila Gentil Rodriguez Cal
}

\section{SciELO Books / SciELO Livros / SciELO Libros}

CAL, D.G.R. As configurações políticas do Trabalho Infantil Doméstico. In: Comunicação e trabalho infantil doméstico: política, poder, resistências [online]. Salvador: EDUFBA, 2016, pp. 309-333.

ISBN: 978-85-232-1870-6. https://doi.org/10.7476/9788523218706.0009.

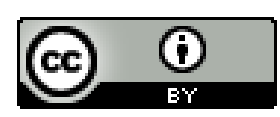

All the contents of this work, except where otherwise noted, is licensed under a Creative Commons Attribution $\underline{4.0 \text { International license. }}$

Todo o conteúdo deste trabalho, exceto quando houver ressalva, é publicado sob a licença Creative Commons Atribição 4.0. 


\section{As configurações políticas do Trabalho Infantil Doméstico}

Dividimos este capítulo em dois momentos: em primeiro lugar, expomos nossas conclusões a respeito do problema de pesquisa sobre como o jogo entre relações de poder atua na configuração política do TID; em segundo lugar, indicamos conclusões gerais sobre o próprio processo de realização desta pesquisa, com objetivo de apontar potencialidades, limitações e recomendações para futuras investigações.

Antes, contudo, consideramos pertinente recuperar a trajetória argumentativa do livro. O principal questionamento que norteou nossa investigação foi como relações de poder (power over, power to e power with) atuam na configuração política do TID,tanto a partir do ponto de vista das próprias envolvidas, no caso, meninas e mulheres ex-trabalhadoras infantis domésticas, quanto no âmbito de visibilidade ampliada dos meios de comunicação, num contexto social em que grupos de advocacy constroem uma luta pública contra esse tipo de trabalho infantil e contam com apoio dos media. 
Ao investigarmos a literatura sobre TID, identificamos que o esquema interpretativo preferencial para análise desse fenômeno baseava-se na ideia de que o TID era uma forma de dominação, cuja base reside em aspectos históricos, sociais e culturais. A partir dessa lógica, o olhar lançado por essas pesquisas a meninas e mulheres que o exercem ou exerceram partiam do pressuposto da dominação e da constituição do estigma e da subalternidade. (ALBERTO et al., 2009; ARAGÃO-LAGERGREN, 2003; BLAGBROUGH, 2008; CARNEIRO; ROCHA, 2009; HASAN; SALEM, 2013; LAMARÃO, 2008)

Desenvolvemos, então, a discussão sobre TID como uma forma de dominação no primeiro capítulo e detalhamos a compreensão dos fatores sociais, culturais e históricos que incidem no TID, como: a circulação de crianças na Amazônia e as tensões entre ser a empregada e ser a "filha de criação"; os pressupostos morais que alimentam a relação de dependência e gratidão/ingratidão entre meninas domésticas e famílias para quem trabalham; lógicas opressivas de gênero que incutam à menina/mulher as obrigações domésticas; aspectos históricos sobre servidão e trabalho das crianças que repercutem no modo com entendemos hoje meninos e meninas trabalhadores; relação entre o pano de fundo das desigualdades sociais e a dominação no TID. Sobre esse último ponto, Carneiro e Rocha (2009) argumentam que haveria um silenciamento social e acadêmico dos dramas que afligem as trabalhadoras domésticas, o que repercutiria nas próprias envolvidas que, segundo os autores, parecem não perceber com clareza a condição em que vivem, pelo "simples fato de que essa condição encerra uma realidade intragável [...]. Nenhum ser humano suportaria viver da verdade de tamanho desvalor social objetivo”. (CARNEIRO; ROCHA, 2009, p. 142)

Tensionamos esse posicionamento ao confrontá-lo com a conceituação do reconhecimento ideológico proposta por Honneth (2007, 2012a), segundo a qual sujeitos podem aderir a formas de subordinação embasados em motivações racionais de que essa adesão pode lhe conferir uma nova conquista ou um novo valor. São racionais porque se baseiam em um sistema de crenças que faz com que as promessas do reconhecimento ideológico sejam consideradas críveis e possíveis de serem alcançadas, o que estimularia, por exemplo, o cumprimento de obrigações sem resistência. (HONNETH, 2007, 2012a) Argumentamos que as promessas relacionadas ao TID são críveis por essa prática figurar como uma oportunidade concreta de "crescer na vida" para meninas pobres, por meio da convivência com uma “boa” família, pelo acesso a bens materiais (celulares, rou- 
pas, computadores, ainda que de segunda mão) e culturais (passeios, viagens), e pela crença de que possibilita acesso a escolas melhores. (MAIA, R.; CAL, 2014)

Desse modo, a perspectiva de Honneth permite uma análise mais nuançada sobre porque as pessoas aderem a lógicas e práticas que podem colocá-las em uma situação de dominação. Contudo, permanece o problema sobre a lacuna, sobre o espaço social e simbólico que se situa entre o reconhecimento ideológico e a luta política propriamente, considerando que, no primeiro, relações de power over são justificadas e suavizadas por um sistema de crenças, o que prejudica a tematização de injustiças e a transformação dos desrespeitos em motivação para a luta. Apesar do enfoque da literatura no TID como uma forma de dominação, acreditamos que complexificar os sentidos acerca do poder e de como ele atua no caso em tela era fundamental, porque nos parecia que, entre aqueles dois polos (reconhecimento ideológico, de um lado, e luta política, de outro), existiria um terreno de disputas, resistências e construção de solidariedade.

Nesse contexto, havia um fator a ser considerado: a luta política pelo enfrentamento do TID foi motivada e impulsionada por organizações de advocacy, o que traz questões importantes a respeito dos papéis dos sujeitos diretamente afetados pelo TID nesse processo. Dedicamos o segundo capítulo a discutir a organização das ações de enfrentamento ao TID por essas organizações e apresentamos o contexto normativo internacional e nacional sobre o tema. A partir de Miguel (2011), Earls (2011) e James (2011), ponderamos que casos de advocacy em favor de crianças e adolescentes trazem implicações específicas à expressão desses sujeitos. Isso porque as falas de especialistas e atores sociais sobre os interesses e as perspectivas de meninos e meninas tendem a ser mais consideradas do que do próprio grupo em questão. Contudo, James (2011) critica essa postura, pois, segundo ele, a cidadania de crianças e adolescentes se aperfeiçoa na medida em que deixam de ser considerados incompetentes e passam a ser vistos como sujeitos capazes. Assim, interessa-nos indagar: como esses sujeitos são posicionados nessa construção pública do TID como um problema, empreendida por grupos de advocacy?

Como ponto de partida em busca de resposta a essa questão, apresentamos, ainda no segundo capítulo, o modo como Cedeca-Emaús e parceiros organizaram o Petid e as estratégias de construção do discurso do TID como um problema social. Merecem destaque as ações de media advocacy que renderam boas aproximações com os media locais e uma parceria firmada institucionalmente com 
um dos dois maiores grupos de comunicação do Pará, as Organizações Rômulo Maiorana (jornal O Liberal). Além disso, o Petid também organizou campanhas publicitárias com objetivo de sensibilizar a sociedade paraense pelo combate ao TID. Ao avaliarmos as peças desenvolvidas, concluímos que o discurso da "invisibilidade", mobilizado pelo Petid em vários momentos, contribuiu para problematizar o TID como um assunto público, porém reforçou a condição de subordinação e subalternidade das meninas afetadas e as posicionou preponderantemente como vítimas, e não sujeitos políticos.

No terceiro capítulo, desenvolvemos os principais referenciais teóricos desta pesquisa acerca do "político" e do "poder". Iniciamos com a pergunta: o que faz com que um problema seja reconhecido como questão política? Para subsidiar a resposta, recorremos essencialmente a três autores: Habermas, Mansbridge e Honneth. Segundo Habermas (2003), qualquer tema pode adquirir status de político, desde tenha sido objeto de escrutínio público. Por meio desse processo, os interesses ou demandas em questão podem alcançar as instâncias políticas responsáveis e, talvez, serem sintetizados em propostas e ações. (HABERMAS, 2003) Para Mansbridge (1999), não haveria enfoques pré-políticos se o assunto em questão é algo que mereça ser discutido por duas ou mais pessoas. Assim, atos de resistência e questionamento cotidianos podem ser considerados políticos. Por isso, Mansbridge $(1999,2009)$ valoriza o lugar das conversações informais e dessas disputas políticas fincadas no dia a dia. Honneth (2003), por sua vez, ressalta que experiências de desrespeito podem se converter em motivações para lutas políticas e incentivar a construção de contexto comum de ação. Ele defende que a constituição de identidades possui um caráter político e que a política também está vinculada ao cotidiano na medida as identidades são construídas de modo intersubjetivo. (HONNETH, 2003; MENDONÇA, 2012) A nosso ver, trata-se de abordagens complementares. A partir de Habermas, podemos compreender o processo mais amplo de atuação política de enfrentamento ao TID, que estimulou debates públicos e tomadas de decisão institucionais por meio da ação dos agentes de advocacy. Com Mansbridge e Honneth, podemos compreender atos políticos que têm espaço no cotidiano e suas vinculações com essa visada mais pública do processo. Tomando como base esse horizonte teórico, consideramos que o processo de politização do TID poderia passar por, pelo menos, quatro momentos: aceitação, resistência, demonstração da injustiça e construção de luta política a partir dos próprios envolvidos. 
Consideramos que certo jogo entre relações de poder incide nessas configurações políticas do TID e, para investigar essa possibilidade, utilizamos como ponto de partida a sistematização elaborada por Allen (1998, 2000). Como já discutido, essa autora entende que relações de poder são fenômenos complexos que exigem uma abordagem nuançada. Assim, ela propõe uma distinção analítica entre power over, power to e power with, os quais entende como faces de uma mesma moeda, mas que permitem a distinção analítica das situações investigadas. (ALLEN, 1998, 2000) Relacionamos a proposta de Allen com outras conceituações sobre poder com objetivo de organizar o debate teórico sobre o assunto e possibilitar ainda um maior refinamento das análises.

Para discussão sobre power over, por exemplo, recorremos a Lukes, que articulou essa faceta do poder a partir de três dimensões. A primeira, unidirecional relacionada a conflito observável entre partes com interesses antagônicos em que o ator mais poderoso constrange as escolhas possíveis do outro e o faz tomar decisões que de outra forma não faria. (DAHL, 1957) A segunda, bidimensional, diz respeito a conflitos não observáveis em que há uma "mobilização de disposições" (BACHRACH; BARATZ, 1962), de modo a assegurar que apenas os temas considerados seguros, por não ameaçarem os interesses das elites dominantes, sejam colocados na agenda pública. A terceira, tridimensional, considera processos latentes de dominação e entende poder como a capacidade de afetar o outro significativamente, ainda que de modo subjacente e não explícito ao sujeito concernido. (LUKES, 1980, 2005) Como afirma Perissinoto, "trata-se de um poder que não produz ameaças, mas sim o convencimento e a submissão simbólica ao estado das coisas”. (PERISSINOTO, 2008, p. 15)

Outra faceta do poder com a qual trabalhamos é power to. Segundo Allen (1998, 2000), é a capacidade de atingir um ou vários objetivos e faz referência à construção e perseguição de projetos de vida. Empoderamento e resistência são formas específicas de power to. Por fim, a última distinção analítica de poder que consideramos é power with, que diz respeito à construção de uma vontade comum e à capacidade de "agir em concerto". (ARENDT, 1994) A solidariedade é o modo principal de aplicação desse aspecto do poder e participa da constituição de ações coletivas. De acordo com Honneth (2003), para formação de lutas políticas, é preciso conectar experiências pessoais de desrespeito e injustiças a algo que concerne a todo um grupo. Essas distinções entre power over, power to e 
power with permitiram o exame das relações de poder no TID por meio de outros vieses, e não apenas o da dominação.

Ainda no terceiro capítulo, discutimos as tensões entre poder e desigualdades. Se o contexto social é marcado por profundas desigualdades e assimetrias de poder, qual o espaço para a agência autônoma dos sujeitos oprimidos? Souza (2009) defende que haveria "consensos inarticulados" que atuariam na manutenção das desigualdades sociais e que não permitiriam a reação dos sujeitos em vulnerabilidade (da "ralé”) porque fazem com que o caráter estrutural da dominação não seja percebido. Para esse autor, existe uma espécie de segunda natureza que orienta nossas ações e posicionamentos no mundo. Ele defende ainda que existem condições imateriais que atuam na formação de classes sociais, e que essa reprodução afetiva tácita faz com que alguns indivíduos nasçam destinados ao sucesso (classe média) enquanto outros destinados ao fracasso (ralé). De acordo com Souza, "não existe futuro para quem é escravo de suas necessidades e inclinações naturais imediatas”. (SOUZA, 2009, p. 415)

Como contraponto à posição de Souza (2009), consideramos as perspectivas de Biroli (2012, 2013) e Brites (2000, 2003). A primeira autora defende a ideia de que não podemos definir os posicionamentos de mulheres simplesmente como resultantes de processos de opressão porque isso seria deixar de lado questões relativas às experiências subjetivas e às possibilidades de brechas no sistema de reprodução das desigualdades. (BIROLI, 2013) Ela defende ainda a ideia de uma "agência imperfeita” como expressão regular da agência individual das mulheres, porque considera o contexto social e os constrangimentos que atuam sobre esse gesto, mas mantém em aberto a possibilidade de crítica e questionamento. (BIROLI, 2012) A segunda autora, Brites (2003), alerta que devemos nos distanciar de visões teóricas dominantes para podermos enxergar as particularidades das práticas políticas de trabalhadoras domésticas.

No quarto capítulo, apresentamos as razões pelas quais decidimos analisar a configuração política do TID tanto a partir das perspectivas dos media quanto das afetadas e indicamos o percurso metodológico que percorremos nesta pesquisa. Os media foram escolhidos por constituírem a esfera central de visibilidade acerca do assunto - na qual discursos em torno do TID foram mobilizados, atualizados e construídos - e também por exercerem um papel, reconhecido pelo Petid, como agentes de advocacy,pelo enfrentamento desse tipo de prática. Embora esse fato seja positivo, era fundamental lançar um olhar mais sistemático 
para avaliar a cobertura sobre o assunto em tela e as suas reverberações para a configuração política do TID. De modo semelhante, precisávamos considerar também as perspectivas das afetadas para compreender como constroem sentidos a respeito do TID sobre e (a partir de) relações de poder. Ao mesmo tempo, os grupos focais constituíram-se como oportunidade para que aquelas meninas e mulheres tomassem a palavra, refletissem sobre aspectos concernentes às suas vidas e a de outros.

Sobre os dois contextos, lançamos algumas questões: há diferenças entre o tratamento dado pelos media ao tema e o modo como esses sujeitos leem as próprias vivências? O TID, como problema político, configura-se do mesmo modo nessa teia discursiva midiática e nos relatos das meninas e mulheres afetadas? O que isso pode revelar, por um lado, sobre a atuação dos media na configuração do TID como questão política e, por outro, sobre a percepção e o entendimento dessas meninas e mulheres acerca da questão? Como corpus empírico, selecionamos 136 matérias jornalísticas sobre TID publicadas de 2000 a 2009 nos dois principais jornais locais do Pará. Além disso, realizamos sete grupos focais como seis perfis distintos: meninas trabalhadoras domésticas não ligadas a programas sociais de combate ao TID; meninas ex-trabalhadoras domésticas ligadas ao projeto social do Cedeca-Emaús; senhoras ex-trabalhadoras infantis domésticas atendidas por projeto social; mulheres jovens ex-trabalhadoras infantis domésticas não ligadas a projetos sociais; mulheres ex-trabalhadoras infantis domésticas empregadas em condomínio de classe média/alta e, por fim, mulheres extrabalhadoras infantis domésticas sindicalizadas. ${ }^{1}$

No quinto capítulo, realizamos a análise de modo comparativo entre as perspectivas do media e dos grupos focais a partir de três grandes temas: (a) definições acerca do TID; (b) vivências no TID (violência e educação) e (c) projeções de futuro e responsabilidades. Nas próximas três seções vamos discutir alguns dos principais achados desta pesquisa por meio de análises transversais entre as diferentes temáticas analisadas.

1 Importante relembrar que foram feitos dois grupos com esse mesmo perfil. Para mais esclarecimentos, consultar nota de rodapé $n^{\circ} 13$, do capítulo quatro. 


\section{CONFIGURAÇÃO POLÍTICA DO TID A PARTIR DOS MEDIA}

A análise das relações de poder empreendida no capítulo anterior permitiu que examinássemos como os jornais estudados posicionaram trabalhadoras infantis domésticas nessa cena discursiva e como atuaram na construção de significados acerca do TID. Por meio da articulação entre os resultados nas diferentes temáticas investigadas, será possível compor o quadro mais amplo da configuração política do TID a partir dos media.

Assim, a divisão entre os três grandes temas destacados - (a) definiçõos acerca do TID, (b) vivências no TID (violência e educação) e (c) projeções de futuro e responsabilidades - possibilitou matizar esse processo e nos permitiu perceber se havia ou não diferenças no modo com os jornais discutiam o TID a partir desses eixos. A seguir, apresentaremos conclusões sobre cada um.

A respeito das “Definições acerca do TID”, a principal relação de poder desvelada foi a de power over, sobretudo a partir de duas perspectivas: em primeiro plano, como conflito entre interesses, de tal forma que o mais poderoso constrange as possibilidades e as escolhas do outro ator de modo significativo (ALLEN, 1998, 2000); em segundo plano, como processos latentes de dominação, sustentados a partir de aspectos internalizados menos acessíveis aos sujeitos afetados (LUKES, 2005), que faz com que as próprias afetadas não percebam as injustiças provocadas pelo TID. Esse último foi o mais recorrente.

O processo de dominação intrínseco ao TID, aos poucos, ao longo da cobertura sobre essa temática, vai aparecendo em suas formas mais explícitas, como a sujeição das meninas trabalhadoras às exigências da patroa, o cerceamento do direito à educação e ao contato com os pais e, ainda, por meio da analogia do TID com o trabalho escravo. Segundo os media analisados, esse tipo de trabalho infantil poderia ser comparado ao escravo em razão do não recebimento de salário, da obrigação de realizar todo o tipo de serviço e da ambiguidade perversa de que a menina doméstica seria parte integrante da família dos patrões (quando o TID, nesse caso, é na casa de terceiros, e não na própria casa).

Nesse contexto, o jornal abriu espaços de fala a meninas e mulheres trabalhadoras infantis domésticas e ex-trabalhadoras. O lugar ocupado pela maioria delas era o de vítimas que sofreram (ou sofriam) de modo passivo com aquela relação dominação. Importante destacar que o sentido de dominação no TID não era mobilizado por elas próprias, mas sim pelo discurso do jornal, de modo 
bastante crítico e ativo. Dessa forma, não há, de modo geral, espaço significativo nos jornais para a atuação política dessas meninas e mulheres. Por esse ponto de vista, foram reduzidas as reações politizadas ao TID pelas próprias afetadas. Raras vezes, o discurso do jornal promoveu um deslocamento do posicionamento como vítima para o de vítima resistente, com capacidade de crítica. Um caso exemplar é o de Aparecida, uma mulher que desde os cinco anos trabalhava como doméstica. No início da matéria, ela figura como vítima orgulhosa por ser tratada como membro da família e pelo patrão só comer dos bolos que fazia. A reviravolta é propiciada pela atuação da jornalista que "explica” a Aparecida o que é “Trabalho Infantil Doméstico". Após essa "revelação", a ex-trabalhadora infantil doméstica exprime a indignação por não haver preocupação por parte do Estado em relação à utilização de crianças como escravas durante sua infância.

Outra forma pela qual essa mudança no posicionamento de vítima ocorreu, foi por meio da referência ao Cedeca-Emaús e a parceiros. A lógica narrativa trabalhada pelo jornal, quando se tratava de dar voz a meninas atendidas pelo Petid, iniciava pelo relato do sofrimento no TID e concluía , na maior parte dos casos, com a mudança na trajetória de vida dessas meninas, que só podia ser propiciada pelo Petid. Assim, encontramos casos em que o lugar destinado a adolescentes ex-trabalhadoras domésticas como resistentes e até mesmo como sujeitos políticos em pouquíssimos exemplos, nos quais, em geral, essas meninas estavam efetivamente engajadas no enfrentamento ao TID após terem sido beneficiadas pelo Cedeca-Emaús e parceiros.

Consideramos que, ainda que essas vozes ganhem espaço nos media, o modo como o TID é configurado como uma questão política nesse âmbito de visibilidade ampliada é de modo extrínseco aos sujeitos diretamente concernidos. Isso porque, pela forma como os media discutiram sobre o TID, é como se as trabalhadoras só tivessem o direito de figurar como resistentes ou sujeitos políticos quando inseridas e apoiadas por programas de enfrentamento a essa prática. É a partir, portanto, da ação de um ator externo, nesse caso, principalmente organizações e grupos de advocacy, que são concedidos espaços de fala a esses sujeitos em papéis que vão além de vítimas.

Ainda sobre as“definições do TID”, evidenciamos a dificuldade que os media tiveram para abordar o trabalho doméstico no seio da própria família da menina. Na verdade, foi um assunto pouco abordado e surgiu de principalmente de modo fortuito no ensejo de matérias sobre outros assuntos que não eram o trabalho in- 
fantil. Quando vinham no escopo de reflexões sobre o TID, imprecisões e ambiguidades acompanhavam as tentativas de distinção entre o trabalho doméstico para a própria família e a contribuição desejável de crianças e adolescentes ao cumprimento de afazeres domésticos. Meninas eram posicionadas como vítimas da dominação patriarcal e de classes, a qual não houve menção à resistência. Entretanto, ao mesmo tempo, em uma das matérias analisadas, o trabalho na própria casa é apresentado como um modo de adquirir habilidades essenciais para a vida futura. Ainda que a maior parte da matéria em questão critique esse tipo de trabalho e denuncie essa situação como grave e recorrente a partir da exposição de dados estatísticos, na segunda parte, é apresentada a história de uma agente comunitária que se orgulha das filhas trabalharem na própria casa, o que faz com que ela consiga dar conta de suas outras obrigações.

Quanto à macrotemática “definições do TID”, concluímos que o modo como o discurso dos media foi construído buscou desvelar e denunciar componentes ideológicos do TID, como: a ambiguidade de ser ou não da família; a ideia de que seria uma forma de ajuda mútua, então não haveria necessidade de salário; a ideia de que não seria um tipo de trabalho propriamente, mas uma ajuda ou um tipo de atividade de menor importância, como "reparar" menino. Assim, a tensão entre as promessas feitas e a sua não realização material destacada pelos jornais levou ao entendimento de que esse trabalho infantil seria uma forma de escravizar crianças e adolescentes, o que foi apontado por atores sociais e a mãe de uma ex-trabalhadora doméstica. Nesse contexto, como já dissemos, o modo prioritário pelo qual as meninas trabalhadoras domésticas foram posicionadas foi como vítimas. Entretanto, não se trata de um terreno plano e homogêneo. A construção dessas vítimas variou entre vítimas que se orgulhavam dos fatores que alimentavam a própria dominação, vítimas escravizadas, vítimas da própria família, vítimas conformadas, vítimas resistentes. Essas últimas, apoiadas principalmente pelo trabalho de organizações sociais.

A respeito da temática "vivências no TID", nas matérias sobre violência, a relação de poder mais evidenciada foi a por power over, na sua acepção mais explícita de dominação que incide sobre o controle do corpo do outro. Ao mesmo tempo, as meninas afetadas são tratadas como vítimas assujeitadas ao poder de mando e aos desejos dos patrões. No geral, não identificamos menções a resistência (ALLEN, 2000; FOUCAULT, 1995) e à possibilidade de motivação para luta a partir da tematização da injustiça do desrespeito. (HONNETH, 2003) A única 
fissura nesse quadro, ainda que pequena e frágil, é a apresentação da vontade de uma ex-trabalhadora infantil doméstica em se tornar delegada, após ter sido extremamente violentada pela ex-patroa e estar sendo atendida por órgãos do sistema de garantia de direitos de Goiânia.

Na cobertura sobre educação, assim como nas matérias da temática "definições do TID”, houve distinções entre o modo como trabalhadoras infantis domésticas e ex-trabalhadoras ligadas ao Petid foram consideradas. Acerca das primeiras, concluímos que, ao contrário do que ocorreu na primeira temática, elas eram posicionadas como vítimas, mas não de relações de poder latentes e internalizadas, de modo a não identificarem como injustiças aquilo que viviam. As meninas ouvidas nas matérias com enfoque sobre educação reconheciam os problemas que advinham do TID e os prejuízos que estavam causando à educação regular. Apesar disso, mostravam-se resignadas ou acostumadas com aquela situação.

Quando uma das meninas manifestou o plano de concluir o ensino médio e trabalhar no comércio, o discurso do jornal simbolicamente demonstrou a distância entre esse sonho e a possibilidade de concretização quando utilizou a palavra "acredita", ao se referir ao posicionamento da adolescente. Mesmo quando essas meninas apontavam o desejo de mudar de vida, havia referências no discurso do jornal de que esse projeto era muito difícil de ser realizado em razão do TID, que faz com que não consigam ter sucesso nos estudos e, assim, alimentam o ciclo da pobreza. Nos jornais analisados, coube principalmente a especialistas e atores sociais o questionamento da violação do direito à educação e também da ineficiência do Estado em garantir melhores oportunidades a essas crianças e adolescentes.

Quando os jornais davam voz a meninas que eram atendidas pelo Petid, o discurso construído era o de que elas estavam mais próximas de realizar os seus sonhos, pois eram assistidas e orientadas pelo Programa. Nesse sentido, quando as falas delas se referiam ao desejo de voltar a estudar, eram posicionadas como resistentes, como sujeitos que estavam tentando sair daquela condição imposta pelo TID, ainda que com ajuda institucional. De modo semelhante, nas matérias que abordaram o tema "perspectivas de futuro", as meninas que podiam vislumbrá-lo eram apenas as atendidas pelo Cedeca-Emaús, de tal forma que entrar no Programa já era considerado um modo de alcançá-lo, de "recuperar o direito de sonhar". 
Quando os jornais abordaram o tema das responsabilidades pelo TID, o apelo era para que a sociedade em geral se envolvesse no combate a esse problema. As meninas afetadas pelo TID eram, então, apresentadas como vítimas em estado de espera, aguardando que outros resolvessem os problemas relacionados a esse trabalho infantil. A quebra nesse quadro foi possível com a participação de uma adolescente atendida pelo Cedeca-Emaús na Caravana Contra o Trabalho Infantil. Nas notícias sobre esse evento, a menina figurou como um sujeito político, com capacidade de cobrar do então governador do Pará, providências para que crianças e adolescentes tivessem condições de vencer na vida.

A partir das análises, podemos realizar três conclusões transversais sobre a configuração política do TID no ambiente midiático analisado: (1) Em primeiro lugar, o modo como as meninas figuraram como personagens nas narrativas jornalísticas nos parece ter reforçado o lugar delas como vítimas. De acordo com Mouillaud (2002), o jornal opera atribuindo sentidos específicos às falas de sujeitos, o que o faz "senhor do efeito que confere às vozes que reproduz". (MOUILLAUD, 2002, p. 121) Ao posicionarem as afetadas pelo TID nessa cena discursiva, os jornais estimularam, de certo modo, um efeito de despolitização desses sujeitos, atribuindo-lhes o papel preponderante de vítimas que, em alguns casos, nem se dão conta do processo de dominação ao qual estão sujeitas, como vimos nas matérias sobre as "definições do TID”, ou vítimas resignadas nas discussões sobre violência e educação, por exemplo.

A nosso ver, a distinção entre personagens e fontes, nesse caso, foi decisiva em termos de politização. Segundo Motta (2007), acerca das narrativas jornalísticas, "personagens são atores que realizam coisas (funções) ma progressão da história”. (MOTTA, 2007, p. 152) No caso em análise, as personagens foram aquelas que sofreram com o TID e têm parte dessa história narrada no relato jornalístico. Por outro lado, especialistas e atores sociais foram posicionados como sujeitos com capacidade de falar politicamente sobre o TID. Eram a eles, majoritariamente, a quem cabiam os discursos sobre os problemas relacionados a essa prática e as discussões sobre as possibilidades de revolvê-los.

Portanto, a construção discursiva dos lugares de fala entre as afetadas e entre especialistas era bem distinta. As primeiras podiam explicitar situações vividas enquanto trabalhavam como domésticas, relatar a rotina diária, a relação com a família empregadora, entre outros. Era, nesse contexto, principalmente, que era permitida voz a esses sujeitos. Assim, apesar de ter havido certo espaço 
nos media para a "autoexpressão dos dominados", o escopo acerca do que poderiam se expressar era, sobretudo, circunscrito à manifestação das mazelas do TID. Já os especialistas e os atores sociais gozavam de um lugar diferenciado na cobertura jornalística. Eles discutiam resultados de pesquisas e lançavam diagnósticos acerca do TID. Por essa razão, eram considerados interlocutores mais apropriados para falar do que seriam os reais interesses de crianças e adolescentes naquela situação porque, capazes de desvelar relações de poder latentes, poderiam vislumbrar caminhos para enfrentar o TID.

Como representantes autoautorizados (URBINATI; WARREN, 2008), os agentes de advocacy falaram em nome das meninas e mulheres afetadas e sobre elas. Para Alcoff (1991), esse gesto participa da construção dos lugares e papéis sociais que eles ocupam. Em algumas situações, a autora afirma que falar por outros é necessário para tratar situações que não seriam problematizadas de outra forma. Contudo, ela afirma que devemos avaliar esse processo a partir da resposta à pergunta se ele permite o empoderamento daqueles em nome de quem se fala. (ALCOFF, 1991) Procurando essa resposta a partir do caso analisado, podemos afirmar que a representação autoautorizada das afetadas pelo TID, por meio dos grupos de advocacy, permitiu a retirada desse tema do âmbito privado e a sua inserção na cena pública, o que estimulou, inclusive, decisões governamentais como a inclusão do TID na lista das piores formas de trabalho infantil. (BRASIL, 2008) Entretanto, os modos pelos quais se concedeu espaço de fala às meninas e mulheres afetadas pelo TID e como se falou sobre elas nos media analisados, em geral, não contribuíram para romper com a posição de subalternidade e, em alguma medida, acabaram por reforçar esse lugar de sujeitos sem capacidade de agir para transformar sua própria realidade.

(2) Uma segunda conclusão a qual chegamos é a de que o lugar de fala de meninas atendidas pelo Petid era relativamente distinto. Ainda que figurassem nas matérias como personagens, cujo valor estava no relato que podiam fazer, a elas era permitido tecer comentários mais críticos sobre o TID. Nessas situações, ficou perceptível a lógica narrativa construída nas matérias, que iniciavam com o sofrimento ocasionado pelo TID e tinham como desfecho a mudança de perspectiva da adolescente em função da entrada no Petid ou, eventualmente, outro programa de combate a esse tipo de trabalho infantil. De acordo com Motta, “a situação inicial de uma narrativa é, quase sempre, um fato de conotações dramá- 
ticas imediatas e negativas, que irrompe, desorganiza e transtorna”. (MOTTA, 2007, p. 149)

Desde 2002, o Cedeca-Emaús já havia delimitado como desafio evitar a superexposição de vítimas na imprensa (como apresentamos no capítulo dois), porém o fazer jornalístico impunha essa necessidade de "humanizar as notícias" por meio de histórias dramáticas de vida de meninas trabalhadoras. Assim, a referência aos sofrimentos vivenciados pelas adolescentes contribuía com a composição de um enredo a partir do qual o TID era problematizado, e a vinculação de adolescentes ao Petid marcava o desfecho com final feliz. Construções como "a vida dela mudou depois do Cedeca" foram recorrentes.

Nos 10 anos de cobertura analisados, não houve, porém, nenhuma matéria com conteúdo crítico sobre o trabalho desenvolvido pelo Cedeca-Emaús e de reflexão sobre as possibilidades concretas das meninas que passaram pelo Petid. Era como se aquela história terminasse ali, com a entrada para o Programa. Isso nos mostra que a tematização do TID nos media analisados foi principalmente provocada pelo Petid, o que repercutiu nos enquadramentos, no espaço de fala dos atores sociais e nos desdobramentos do assunto.

(3) E, em terceiro lugar, a configuração política do TID delineada no espaço de visibilidade midiático ocorreu de modo extrínseco aos sujeitos diretamente afetados. As primeiras notícias foram incentivadas por estudos e pesquisas realizados pela OIT, Unicef e Cedeca-Emaús. Além disso, as ações de media advocacy dessas organizações estimularam uma cobertura condizente com os discursos que essas entidades estavam adotando para estimular a percepção do TID como um problema social. Inclusive a dificuldade enfrentada por essas organizações para distinguir quando tarefas realizadas na própria casa podem ser consideradas trabalho infantil reverberou na cobertura dessa temática, que foi desenvolvida em meio a contradições e ambiguidades, como discutimos no quinto capítulo.

Assim, a politização do TID nos media seguiu os contornos das ações empreendidas pelas organizações sociais envolvidas na transformação desse assunto de uma questão privada em um tema público, concernente a uma coletividade. A dimensão política do TID foi evidenciada por meio da cobertura jornalística que denunciou os problemas que essa atividade representa para crianças e adolescentes e responsabilizou a sociedade em geral pelo seu enfrentamento. Estimulou-se a construção de solidariedade entre a sociedade de modo 
geral pelo combate ao TID, sobretudo por meio de editoriais, porém de modo extrínseco aos sujeitos afetados.

Identificamos, nessa cobertura, menos um jogo complexo entre relações de poder do que um desvelamento de nuances do power over, que variou entre um estado latente de dominação (LUKES, 2005), a capacidade de agir sobre a decisão de outrem (ALLEN, 1998, 2000) e como dominação que demarca a inferioridade e a subalternidade das meninas e mulheres afetadas pelo TID. (SOUZA, 2009) O discurso acerca da resistência, de acordo com o que apresentamos, ocupou pouco espaço nas matérias investigadas e pode ser caracterizado como uma resistência "tutelada" à condição de trabalhadora infantil doméstica, possibilitada pela inserção em programas de enfrentamento.

Assim, a cobertura sobre o assunto foi marcada pela tematização e exploração dos desrespeitos, nos sentidos desenvolvidos por Honneth (2003), que denunciavam as degradações, as humilhações, as violências e as privações de diretos em razão do exercício do TID. De modo complementar, os discursos dos jornais estudados denunciavam recorrentemente o componente ideológico do TID ao evidenciar como falsas as promessas que o engendram, embora pareçam fazer sentido no sistema de crenças nos quais estão inseridas, como a de que o TID é um caminho para ter acesso à educação, por exemplo.

Em suma, a luta que se desencadeou publicamente contra o TID foi empreendida por organizações sociais com apoio dos media e objetivava chamar atenção da sociedade e do Estado para esse problema. Os sujeitos diretamente afetados foram posicionados majoritariamente como vítimas cujos relatos poderiam contribuir para sensibilizar os cidadãos acerca dessa questão. Nesse sentido, considerando o potencial dos media para generalização de processos de debate público e de pré-estruturação da esfera pública, a discussão ampliada sobre o TID como um problema público acabou por marginalizar a capacidade de atuação política das próprias afetadas na definição de quais posturas e políticas deveriam ser adotadas em relação ao TID. E essa situação foi influenciada pela percepção de que elas estavam sujeitas a um processo de dominação que não as permitia ter clareza sobre o que estava acontecendo no TID. Essa dimensão crítica coube aos especialistas e atores sociais. 


\section{CONFIGURAÇÃO POLÍTICA DO TID A PARTIR DAS AFETADAS}

A partir dos grupos focais, a configuração política do trabalho infantil adquiriu contornos ambíguos e problemáticos. Dependendo da temática em discussão e das características dos próprios grupos, eram evidenciados diferentes arranjos entre as relações de poder investigadas (power over, power to e power with), o que, a nosso ver, repercutiu em entendimentos distintos acerca das práticas políticas das meninas e mulheres afetadas pelo TID.

Nas discussões sobre as "definições do TID”, as entrevistadas defenderam posturas críticas sobre algumas das promessas relacionadas ao TID. Por meio das interações nos grupos focais, as participantes desvelaram relações de power over latentes que atuam na manutenção do TID. Um exemplo disso é o questionamento que permeou os grupos sobre se a menina doméstica era ou não membro da família para a qual trabalhava. Em geral, elas esforçaram-se para apresentar argumentos e indícios que justificassem o porquê dessa promessa não ser concretizada. Assim, segundo elas, ser bem tratada e comer "da mesma comida" que a família empregadora não é suficiente para caracterizar aquele suposto vínculo. As entrevistadas apresentaram elementos significativos para balizar essa diferença: quem é da família passa a ceia de Natal junto na sala; quem é da família recebe carinho dos outros membros; quem é da família estuda no mesmo tipo de escola que os filhos dos patrões. O discurso que apresenta a doméstica como parte da família foi colocado pelas entrevistadas como uma forma da patroa dizer, "de casa para fora", que trata bem a empregada e não como algo que se realiza no cotidiano daquelas famílias. Portanto, elas não endossaram um dos pressupostos da dominação no TID que seria o de que as empregadas compartilham do discurso de que fazem parte da família.

De modo semelhante, as entrevistadas também se mostram atentas à dimensão laboral dessa atividade e buscaram afastar o TID de definições segundo as quais se trataria apenas de uma ajuda, e não de um trabalho. Segundo as participantes, sempre é trabalho, ainda que não haja como retribuição o pagamento de um salário. As adolescentes do Centro de Formação afirmaram que o trabalho como babá é o que dá melhores condições para que a adolescente seja estimada pela família empregadora: na medida em que as crianças criam vínculos e ficam dependentes da babá, a família também ficaria, o que poderia trazer mais segurança no emprego para a adolescente. 
Sobre a comparação entre o TID e relações de trabalho escravo, as meninas e mulheres apresentaram uma postura crítica sobre o que aproxima o TID daquelas. Apesar de algumas divergências acerca de quais características do TID eram ou não escravizantes, elas se posicionaram reflexivamente sobre a ideia de que as atividades que a menina faz ou faria na casa de família seriam poucas e leves, questionando assim outra promessa ligada ao TID, que contribuiria para a suavização da dominação.

De modo amplo, partindo da tentativa de articulação entre as visadas sobre poder e práticas políticas, consideramos que, nessa primeira temática, o jogo entre relações de poder no TID revelou gestos de resistência que questionavam aspectos de power over, mas, de modo pontual e, de certa forma, individualizado, com objetivo de melhorar as condições nas quais ele é realizado.

Encontramos essa mesma configuração política na temática "projeção de futuro e responsabilidade". Em relação às perspectivas de futuro, a maioria das participantes dos grupos focais criticou a possibilidade de conseguir um bom futuro por meio do TID e vislumbrou, ainda que em planos, alternativas para sair da condição de trabalhadoras domésticas. Sobre as responsabilidades pelo TID, elas, em geral, se autorresponsabilizaram pela entrada nesse trabalho, porque seria um modo de conquista relativa de autonomia e de fazer frente à dominação patriarcal. De maneira complementar, elas também atribuem responsabilidade aos governos pelas causas do TID e também pela ausência de políticas, como cursos profissionalizantes e bolsas para jovens. As entrevistadas do grupo "condomínio" apontaram incongruências na postura do Estado, que proíbe o trabalho infantil, mas não oferece condições para que crianças e adolescentes estudem com qualidade e se desenvolvam.

Por outro lado, nos temas "educação e trabalho infantil na própria casa”, a articulação entre as relações de poder desveladas nas discussões dos grupos revelou como postura prevalente a aceitação, que atua na geração de conformismo e resignação. A forma pela qual meninas e mulheres discutiram sobre as questões relativas à educação corroborou em vários aspectos as proposições de Souza (2009) sobre a naturalização das desigualdades sociais por meio da crença na meritocracia e na igualdade de oportunidades, o que pode ser percebido na individualização da culpa pelo fracasso escolar, que algumas das entrevistadas se impuseram, ou ainda na manifestação do desejo de voltar a estudar apenas para adquirir o direito de pagar meia-passagem no transporte público. 
Nesse contexto, possibilidades de resistência aparecem como lampejos ou tentativas conformadas às imposições dos patrões, como no caso de Carol, que precisou repetir o ano porque a empregadora exigiu que ela estudasse à noite, quando havia apenas turmas de supletivo. Como contraponto dentro dessa temática, no grupo "sindicato", a participante Zezé fez um apelo coletivizante acerca da capacidade das empregadas domésticas mudarem a própria vida, desde que queiram e lutem. Apesar disso, o modo como ela individualiza esse aspecto, como se bastasse a adolescente lutar para que ela conseguisse superar o TID, pode reenquadrar a situação na lógica defendida por Souza (2009), que faz com que as desigualdades sejam consideradas justas porque resultantes do esforço individual e do desempenho de cada um, num quadro de igualdade de oportunidades. Contudo, não podemos desvalorizar a aposta na capacidade de agência desses sujeitos, quando afirmam que "podem" lutar e melhorar as suas condições de vida.

Quanto ao trabalho na própria família, esse foi um assunto em que encontramos o maior nível de aceitação. Apesar de algumas meninas e mulheres problematizarem aspectos relacionados a esse tipo de trabalho, como, por exemplo, a exigência que só as filhas cuidem das tarefas da casa, algumas delas demonstram compartilhar dessa mesma lógica opressiva de gênero, segundo a qual as atividades domésticas são essencialmente femininas. Entre as meninas do Centro de Formação, essa situação não é sequer considerada trabalho, e sim uma obrigação das filhas perante os pais, especialmente a mãe.

As discussões a partir da temática "violência" trouxeram um contorno distinto à configuração política do TID. O que as meninas e, principalmente, as mulheres apresentaram eram formas bastante graves de desrespeito, marcadas pela tentativa de dominação não apenas do trabalho do outro, mas do corpo, o que provoca "um grau de humilhação que interfere destrutivamente na autorrelação prática de um ser humano, com mais profundidade do que outras formas de desrespeito”. (HONNETH, 2003, p. 215) A desconsideração das queixas das adolescentes por parte dos patrões, as tentativas de abuso e os estupros fizeram parte dos relatos discutidos pelas participantes. Embora vítimas de violências graves, algumas das entrevistadas demonstraram modos de resistência e buscaram evidenciar as injustiças vividas no trabalho infantil, não apenas do ponto de vista individual, mas também do coletivo, como injustiças vivenciadas por um grupo. Nesse caso, o sofrimento e a vexação atuaram como impulsos para que elas tematizassem injustiças e mostrassem alguma disposição para ação, com vistas à 
transformação daquela realidade, como afirmou Zezé (p. 244): “Mas é por isso que nós devemos lutar, para que as outras trabalhadoras, as outras pessoas que vem aí pela frente, vejam o trabalho e que este trabalho pode ser mudado”.

Esse olhar nuançado nos permite melhor compreender os posicionamentos políticos dessas meninas e mulheres, pois não os considera apenas como resultantes de processos de dominação (ALLEN, 1998, 2000), ou ainda de consensos inarticulados "in-corporados" que determinariam, "desde o berço" as possibilidades de cada sujeito. (SOUZA, 2009) Evidenciou-se, por exemplo, que o poder como power over atuava tanto em direção a uma conformação às lógicas existentes (como no caso do trabalho para a própria família), na individualização da culpa e das possibilidades de "vencer por meio" do TID determinadas pelo esforço pessoal, em formas de humilhação e ameaça, quanto poderia suscitar resistências e motivação para ação (como no caso da violência). Ao mesmo tempo, o power to motivou questionamentos críticos sobre as falsas promessas relacionadas ao TID e a construção de estratégias para que os patrões se tornassem dependentes das empregadas, ou ainda, formas de resistência marcadas de certo modo inócuas pela fragilidade, como dormir vestindo várias camadas de roupa para evitar o contato com o patrão. Nesse sentido, as referências teórico-metodológicas de Allen (2000) contribuíram para matizar os modos intrincados pelos quais as relações de poder envolvidas no TID são articuladas na construção de sentidos sobre a configuração política dessa prática a partir das próprias afetadas.

Nossos achados confirmam que esse processo não consiste em uma lógica organizada e sistemática, mas sim é permeado por ambivalências e ambiguidades, com avanços e retrocessos em relação à politização do trabalho infantil como um tema que concerne a uma coletividade. Se, quando tematizam violência, as entrevistadas preocuparam-se em demonstrar as injustiças que o TID provoca, quando se referiram à educação ou ao trabalho na própria casa, mostram-se resignadas ou envoltas na crença da igualdade de oportunidades e na individualização da culpa.

O caráter político do TID como assunto sobre o qual duas ou mais pessoas deveriam discutir é evidenciado por meio das críticas feitas pelas entrevistadas acerca do modo como ele se concretiza e dos prejuízos que provoca na vida de meninas e mulheres. Assim, considerando, tal como Mansbridge (1999, 2009), que política tem a ver com a forma pela qual se constrói, por meio do discurso, sentidos sobre uma situação comum, podemos afirmar que as participantes 
dos grupos focais dotaram o TID de um conteúdo político que trouxe implicações para a tomada de posição e para a decisão, ainda que ligadas a escolhas cotidianas. Segundo Mansbridge $(1999,2009)$, pequenos atos podem ser gestos políticos. Assim, essa conotação política pode ser percebida a partir de atos aparentemente simples, como, por exemplo, dizer que não é função da trabalhadora infantil doméstica deitar-se com patrão, ou ainda, decidir não voltar para casa de um patrão explorador. Ao longo dos relatos dessas situações, as entrevistadas apresentaram argumentos e histórias para justificar porque o TID deve ser considerado um assunto que merece atenção coletiva.

Nesse sentido, evidenciamos a pertinência e a proficuidade de considerar as possibilidades de agência dessas meninas e mulheres sempre tensionadas com constrangimentos estruturais. Não se trata de optar por um viés ou outro. Elas não são nem oprimidas por completo, nem completamente resistentes. A riqueza está na tensão entre um lugar e outro, entre gestos de identificação e de desidentificação com os papéis e lugares que são atribuídos a elas e que, ao mesmo tempo, compõem seus modos de ver a própria situação.

\section{TID COMO PROBLEMA PÚBLICO POLÍTICO}

No primeiro capítulo, argumentamos que pesquisadores e atores sociais recorreram ao discurso da invisibilidade para denunciar o TID como problema. Isso porque, em razão de fatores históricos e culturais, essa atividade não seria reconhecida como um trabalho de fato, ou ainda por ocorrer nos lares de família, um ambiente protegido dos olhares públicos. O Petid utilizou de modo amplo o discurso do combate à invisibilidade dessa prática nas peças publicitárias que desenvolveu e reverberou essa ideia por meio do acesso aos media estudados. Dessa forma, os esforços do Cedeca-Emaús e de outras organizações que fizeram advocacy contra esse tipo de trabalho infantil consistiam no questionamento público dessa prática por meio da denúncia de sua invisibilidade, dos prejuízos aos direitos da criança e do adolescente e também do estímulo ao engajamento social para o seu enfrentamento. A ideia era estimular um processo de debate público que desvelasse os problemas do TID e contribuísse com a transformação cultural, ao retirá-lo da "invisibilidade”, do limbo das práticas não questionadas. (CENTRO DE DEFESA DA CRIANÇA E DO ADOLESCENTE, 2002) 
No espaço de visibilidade dos media, como já apresentamos, as vozes preponderantes eram de atores sociais do Cedeca-Emaús ou parceiros. Quando adolescentes eram chamadas à cena, o eram, sobretudo, como vítimas, como sujeitos que manifestavam o sofrimento do TID. É razoável afirmar que, para que algo seja visto como um problema, é preciso haver vítimas que tornem concretos os danos causados por ele. Assim, as trabalhadoras infantis domésticas cumpriram majoritariamente esse papel no espaço de visibilidade ampliada dos jornais acerca do TID, impulsionado pelas organizações sociais. Por meio das análises de especialistas e atores sociais, os dramas e vivências particulares reforçaram o argumento de que essas questões tidas como pessoais são políticas também.

Contudo, não houve um conflito explícito, nos media investigados, entre partes antagônicas ou deliberantes acerca desse assunto. A abordagem, em geral, foi de crítica ao TID, mas não estimulou um debate sobre o assunto internamente aos jornais. Entendemos que a expectativa de atores sociais e agentes da mídia era que esse conflito se daria em outro âmbito, na interseção entre o questionamento ao TID e os discursos legitimadores dessa prática espraiados pela sociedade. Porém, considerando a capacidade dos media em pré-estruturar a esfera pública (MAIA, R., 2008b; MENDONÇA, 2006), o modo como o lugar de fala de meninas e mulheres afetadas foi construído nesses espaços, a nosso ver, reforçou a posição marcada por relações de power over na qual esses sujeitos são enquadrados em nossa sociedade.

Nesse sentido, a luta discursiva desencadeada publicamente contra o TID no contexto analisado não só deixou de ocorrer a partir do ponto de vista das concernidas, como também as posicionou principalmente apenas como vítimas e, portanto, sujeitos destituídos de capacidade de fala e tomada de posição políticas. As exceções nesse cenário corresponderam às adolescentes empoderadas a partir da inserção em projetos sociais. É necessário reconhecer que os media abordaram o assunto por conta do trabalho de advocacy desenvolvido por organizações sociais locais e internacionais. Elas, portanto, tiveram um papel essencial na tematização do TID, porém a forma como isso se concretizou deu a ver contradições entre a inclusão de adolescentes com papéis ativos nessas iniciativas (como preconizado nos guias e manuais dessas organizações) e o uso ilustrativo de suas falas.

O movimento de advocacy foi importante para chamar atenção do Estado contra esse tipo de trabalho infantil. Pelo que analisamos em relação às práticas 
políticas dessas meninas e mulheres, inferimos a dificuldade de construção de ação coletiva a partir delas próprias em relação ao TID, sobretudo porque, apesar de manifestarem resistências ao TID e demonstrarem injustiças vivenciadas neles, seus projetos não caminham para a construção de uma identidade coletiva que as organize num movimento estruturado contra essa prática ${ }^{2}$. Nesse sentido, as ações de grupos de advocacy podem ter uma contribuição decisiva, porém na medida em que abram espaço para que elas tomem a palavra, de modo que o que dizem não seja apenas considerado resultado de operações de power over. Assim, por meio das ações de organizações sociais, o tema entrou na pauta política institucional, mas não podemos falar ainda de um amplo debate na sociedade acerca desse assunto, o que contribui para a sua manutenção e para a busca por saídas e soluções políticas que não passam, de modo amplo, pelas considerações dessas mulheres. Essa percepção é compartilhada de certo modo pelas meninas e mulheres afetadas que expressaram o desejo de que suas vozes e seus gestos de tomar a palavra fossem considerados e compartilhados o máximo possível.

Nesse contexto, um fato recente fornece novos elementos a serem investigados: a aprovação, em 6 de Junho 2013, e a regulamentação, em 1 de Junho de 2015, da Proposta de Emenda Constitucional 66/2012, conhecida com a "PEC das Domésticas”, que busca equiparar os direitos dos trabalhadores domésticos aos dos outros trabalhadores. Em primeiro lugar, quais as implicações dessa norma para o TID? Será que a regulamentação de direitos para o trabalhador doméstico adulto poderá incentivar a inserção de crianças e adolescentes nesse tipo de serviço? E, sobre as relações de poder, especificamente, a equiparação de direitos e deveres entre domésticos e outros trabalhadores contribuirá para empoderar os primeiros ou subjugá-los?

Apesar de significar um avanço acerca do modo como domésticas são vistas pela nossa sociedade, a equiparação de direitos é acompanhada por uma série de exigências, de tal forma que cumprir rigorosamente o contrato pode desfavorecer as domésticas. Como já questionava Brites em 2003,

2 Apesar de existirem entidades associativas de trabalhadores domésticos, como sindicatos e federações, a atuação deles não ganhou preponderância na cena pública. Nesse sentido, o papel desses grupos e associações no enfrentamento do TID e na garantia dos direitos de trabalhadores domésticos é um tema que merece novas investigações. 
[...] até que ponto pode uma empregada doméstica cumprir aviso prévio de 30 dias, ou pagá-lo, quando a natureza do serviço as coloca numa relação tão direta com seus patrões? [...] Quem define as noções de bom cumprimento das tarefas domésticas estipulado implicitamente no contrato? (BRITES, 2003, p. 77)

Poderíamos acrescentar: em quê a emenda constitucional e sua posterior regulamentação se aproximam dos desejos, interesses e perspectivas das mulheres diretamente afetadas? Como essa construção normativa abriu-se e se deixou influenciar pela fala dessas mulheres? A nova legislação modifica a teia das relações de poder na qual essas mulheres se inserem e estão inseridas?

\section{ALGUNS APONTAMENTOS SOBRE O PROCESSO DE PESQUISA}

Moderadora: E vocês, o que vocês acharam desse nosso bate-papo?

Maria: Olha, eu gostei. Nós botamos muitas coisas que acontecem, muitas coisas que... Varias opiniões, não é? Lógico que tem umas pessoas que discordam de umas certas coisas, mas é muito bom esclarecer, falar das coisas que nós vivemos aqui, passamos por momentos difíceis e que hoje vamos tentar superar, não é?

Nanã: Eu também gostei. Teve algumas coisas que não, porque eu lembrei de muitas coisas que eu passei... [Risos]

Carol: Relembra o passado, não é?

Nanã: Quando eu era menina, não é? Mas foi legal, foi bom e eu espero que te ajude para o seu doutorado, não é? Pois é.

Maria: E que mude também, não é? Muita coisa.

Carol: É porque isso aqui vai servir, não é? Para quando as pessoas ouvirem vai servir para que haja uma mudança através disso aqui, porque poucas pessoas fazem isso, não é? Tem esse projeto para fazer, talvez tendo isso vai abrir os olhos deles, muitas pessoas vão ouvir, não é? Pessoas que são importantes lá... [Risos] Nanã: Eu achei muito legal que a faculdade esteja usando essa coisa para mostrar que muitas meninas são escravizadas no nosso país e quem sabe no futuro vocês se tornam todas doutoras [aponta para as outras participantes] e vão ajudar a gente. [Risos] (CASA DA PATROA) 
A discussão final no grupo "casa da patroa” representa alguns dos desafios que vivemos na realização dos grupos focais. Nosso entendimento era que, como se tratavam de espaços de interação, a dinâmica desses grupos contribuiria para o desvelamento das relações de poder que atravessam o TID, e isso significou lidar com a discussão sobre temas sensíveis, com expressões de dor e de indignação. Nesse contexto, o pesquisador/moderador é também sujeito de interlocução, que participa daquela cena, que a vive.

Enquanto nos media, as meninas e mulheres afetadas pelo TID tiveram voz (nas condições que apresentamos anteriormente), nos grupos focais, por estarem entre sujeitos com experiências semelhantes, elas tomaram a palavra e manifestaram os posicionamentos, os dilemas e as tensões que analisamos a respeito do TID. Construímos categorias de análise para buscar compreender nuances do fenômeno estudado de modo reflexivo e em tensão entre o que (e como) elas diziam, os textos dos media e os aportes teóricos que mobilizamos. Esse movimento mostrou-se produtivo na medida em que evidenciou a complexidade das relações de poder que atuam, de formas distintas, na configuração política dessa prática.

No entanto, confrontamo-nos com a impossibilidade de dar conta do gesto de tomada de palavra daquelas meninas e mulheres na integralidade. Ao terminarmos a pesquisa, por exemplo, um elemento não apresentando antes, chamanos atenção: o compromisso que exigiam da pesquisadora.

Zezé: Sobre esse teu trabalho, esse trabalho é muito importante. Sobre essa nossa conversa: vai ficar só aqui ou tu vais relatar ao público?

Ericka: É porque ela é jornalista! Tem que levar para frente...

Moderadora: Eu só não vou divulgar os nomes reais de vocês. O que a gente conversou vai virar um trabalho, um relatório, vai virar artigos que eu vou apresentar em vários lugares diferentes.

Ericka: Ela vai aumentar a matéria...

Moderadora: Agora eu não vou escrever, pelo menos por agora, para o jornal, mas eu vou ajudar em outros espaços. Mas para o jornal agora... Mas pode ser. Pode ser que depois que eu termine a pesquisa, eles se interessem, como foi na minha..., em outra pesquisa que eu fiz também sobre o trabalho doméstico. Aí saiu a matéria no jornal, mas eu não posso garantir isso para vocês. Mas vai ser bastante estudado.

Zezé: Tá ótimo! 
Ericka: Isso aqui pode fazer até um livro, não é?

Moderadora: Pode.

Fofa: Que eles lutem.

Ericka: Para as pessoas comprarem e divulgarem essa palestra, não é?

Moderadora: Isso vai ser estudado nas universidades. Isso que vocês estão falando aqui as pessoas vão estudar nas universidades. Quando eu der aula, minha professora der aula, eles vão ouvir e vão ler o que vocês falaram.

Zezé: Está ótimo! (SINDICATO II)

Por fim, elas poderiam falar, mas esse gesto de nos conceder a escuta não era gratuito. Elas exigem o compromisso da pesquisadora com a propagação daquilo que disseram, de suas reivindicações, sofrimentos, demandas. Deixam claro seu desejo de serem ouvidas, de serem consideradas em ambientes nos quais normalmente não o são, como as universidades. Dessa forma, todas elas tiveram um papel ativo nesta pesquisa. Nesse sentido, participar dos grupos e tomar a palavra para nomear o TID e suas consequências já era, por parte delas, um ato político de engajamento na configuração pública dessa questão. 